\title{
Site-specific pre-evaluation of bioremediation technologies for chloroethene degradation
}

\author{
S. S. Patil · E. M. Adetutu • P. J. Sheppard • \\ P. Morrison • I. R. Menz • A. S. Ball
}

Received: 30 October 2012/Revised: 24 June 2013/Accepted: 30 September 2013/Published online: 11 October 2013

(C) Islamic Azad University (IAU) 2013

\begin{abstract}
Groundwater systems are important sources of water for drinking and irrigation purposes. Unfortunately, human activities have led to widespread groundwater contamination by chlorinated compounds such as tetrachloroethene (PCE). Chloroethenes are extremely harmful to humans and the environment due to their carcinogenic properties. Therefore, this study investigated the potential for bioremediating PCE-contaminated groundwater using laboratory-based biostimulation (BS) and biostimulationbioaugmentation (BS-BA) assays. This was carried out on groundwater samples obtained from a PCE-contaminated site which had been unsuccessfully treated using chemical oxidation. BS resulted in complete dechlorination by week 21 compared to controls which had only $30 \%$ PCE degradation. BS also led to a approximately threefold increase in 16S rRNA gene copies compared to the controls. However, the major bacterial dechlorinating group, Dehalococcoides (Dhc), was undetectable in PCE-contaminated groundwater. This suggested that dechlorination in BS samples was due to indigenous non-Dhc dechlorinators. Application of the BS-BA strategy with $D h c$ as the augmenting organism resulted in complete dechlorination by
\end{abstract}

Electronic supplementary material The online version of this article (doi:10.1007/s13762-013-0383-0) contains supplementary material, which is available to authorized users.

S. S. Patil $(\bowtie) \cdot$ I. R. Menz

School of Biological Sciences, Flinders University of South Australia, Adelaide, SA 5042, Australia

e-mail: pati0018@flinders.edu.au

S. S. Patil · E. M. Adetutu - P. J. Sheppard · P. Morrison .

A. S. Ball

Department of Applied Biosciences, Royal Melbourne Institute of Technology, Bundoora, VIC 3083, Australia week 17 with approximately twofold to threefold increase in 16S rRNA and Dhc gene abundance. Live/dead cell counts (LDCC) showed 70-80\% viability in both treatments indicating active growth of potential dechlorinators. The LDCC was strongly correlated with cell copy numbers $(r>0.95)$ suggesting its potential use for low-cost monitoring of bioremediation. This study also shows the dechlorinating potential of indigenous non- $D h c$ groups can be successfully exploited for PCE decontamination while demonstrating the applicability of microbiological and chemical methodologies for preliminary site assessments prior to field-based studies.

Keywords Chlorinated compounds - Biostimulation · Bioaugmentation - Quantitative PCR · Cell viability

\section{Introduction}

Improper disposal and storage of chlorinated compounds has led to widespread contamination of subsurface resources by chlorinated aliphatic contaminants such as tetrachloroethene (PCE), trichloroethene (TCE), dichloroethene (DCE) and vinyl chloride (VC) (SCRD 2007). Due to their toxicity and suspected carcinogenic properties, monitoring the effective remediation of this group of contaminants has gained wide public and academic interest. Standard remedial approaches such as in situ chemical oxidation (ISCO) and pump-and-treat methods have proven to be ineffectual and costly in terms of removing these substances from the environment. To date, enhanced in situ bioremediation has proved to be a promising technique for chloroethene bioremediation (Aulenta et al. 2006; Ernst 2009). This strategy involves the delivery of organic substrates into the groundwater for the purpose of stimulating 
growth and development of native microbial populations (biostimulation) by creating an anaerobic groundwater treatment zone generating hydrogen through fermentation reactions (ESTCP 2004, 2005). In some cases, specific microorganisms known for their dechlorinating capabilities may be added (bioaugmentation), but only if the natural microbial population is incapable of efficiently performing the required transformations (Löffler and Edwards 2006; Schaefer et al. 2010).

To stimulate the activity of desired indigenous dechlorinating microbes at contaminated sites, the redox conditions need to be created (especially in wells which are not completely anoxic) or maintained. This can be achieved by the addition of easily oxidizable organic carbon substrates such as acetate, lactate, butyrate, propionate, hydrogen releasing compounds (HRCs), vegetable oils and molasses (Ballapragada et al. 1997; Fennell et al. 1997; He et al. 2002; Ibbini et al. 2010; Lee et al. 2000). For bioaugmentation of chloroethene-contaminated sites, various members of the Chloroflexi phylum such as Dehalococcoides ethenogenes strain 195, GT, BAV-1, FL2, CBDB1, KB1/VC are commercially available, e.g. KB-1, Pinellas, Bio-Dechlor, SDC-9 cultures and are well known for completely reducing PCE to the environmentally safer ethene (Cichocka et al. 2010; Cheng et al. 2010; Cupples et al. 2003; Duhamel et al. 2004; Ellis et al. 2000; He et al. 2003, 2005; Hendrickson et al. 2002; Ibbini et al. 2010; Lendvay et al. 2003; Major et al. 2002; Müller et al. 2004; Schaefer et al. 2010; Sung et al. 2006). For site owners and bioremediation consulting companies, estimation of the degradation potential, the regulatory requirements and economics of the overall process at a contaminated site are important for selecting the appropriate remediation strategy. If biostimulation reduces the time and leads to meeting key bioremediation endpoints within the desired timeframe, it may well reduce the cost as less monitoring is required. On the other hand, some regulators like the Australian EPA discourage an introduction of foreign organisms to any environment that could stand a chance of causing mutation in indigenous organisms and adversely affecting the biome (Ball 2012). In such cases (as in this study), application of a bioaugmentation strategy can increase the time required for permits, inoculum and remediation costs.

This study was carried out to assess the remediation of PCE-polluted environments using biological strategies. Specifically, this study evaluated the impact of biostimulation alone (BS) and biostimulation combined with bioaugmentation (BS-BA) on the degradation of chloroethene in groundwater enrichment cultures. This involved assessment of the dechlorinating potential using laboratory-based experiments prior to future in situ anaerobic bioremediation. It is believed that the data obtained from this study would provide a better understanding of the feasibility of each treatment for site-specific applications. The bioremediation strategies were applied to PCE-contaminated groundwater obtained from a study site located in Victoria, Australia, which had been previously unsuccessfully treated using ISCO by injecting modified Fenton reagents such as hydrogen peroxide with iron chelate catalysts. To successfully apply the bioremediation approach over the failed ISCO attempt, we chose electron donors such as acetate for biostimulating dechlorinating organisms. A consortia of Dehalococcoides (Dhc) strains FL2, BAV-1 and GT was used for bioaugmentation. Time-intensive studies were performed intermittently to give a more detailed picture of comparative culture performance during which the biodegradation of electron donors and the formation of dechlorination products were documented. 16S rRNA dechlorinator-targeted quantitative real-time PCR (qPCR) was used to monitor the abundance of dechlorinating populations throughout the treatments to determine the extent of their growth in relation to the rate of chloroethenes removal. In addition, a live/dead cell count (LDCC)-based assay was conducted for quick monitoring of dechlorinating microbial cell viability during dechlorination.

\section{Materials and methods}

\section{Chemicals}

All chlorinated ethenes, ethene and other chemicals for microcosm preparation and analytical measurements were purchased from Sigma-Aldrich (NSW, Australia) with a minimum purity of $99.5 \%$. All gases were ordered from Coregas (VIC, Australia).

\section{Groundwater sample collection}

Since 1935, the study site located in Victoria, Australia, has a history of commercial industrial activities. The latest commercial activity at the site was foam manufacturing. Initial investigations identified chemicals of concern including PCE which has formed dense non-aqueous phase liquid (DNAPL) pools acting as a long-term source of contamination. Based upon varying PCE concentrations at different locations, groundwater samples from four different monitoring wells (MWs 1-4) were collected using the protocol suggested by Ritalahti et al. (2010). Temperature, $\mathrm{pH}$, redox potential, specific conductance and dissolved oxygen were measured in groundwater that was pumped through a flow cell (YSI, VIC, Australia) onsite, with a pH/ $\mathrm{mV} / \mathrm{EC} / \mathrm{T} / \mathrm{O}_{2}$ multi-parameter and corresponding probes (YSI) (Table 1). 
Table 1 Field characteristics of groundwater samples at the time of collection

\begin{tabular}{lclllclcl}
\hline $\begin{array}{l}\text { Monitoring } \\
\text { well }\end{array}$ & $\begin{array}{l}\text { Initial PCE } \\
\text { concentration }(\mu \mathrm{g} / \mathrm{l})\end{array}$ & $\begin{array}{l}\text { Temp } \\
\left({ }^{\circ} \mathrm{C}\right)\end{array}$ & $\mathrm{pH}$ & $\begin{array}{l}\text { Eh } \\
(\mathrm{mV})\end{array}$ & $\begin{array}{l}\text { Dissolved oxygen } \\
(\mathrm{ppm})\end{array}$ & $\begin{array}{l}\text { EC } \\
(\mathrm{uS} / \mathrm{cm})\end{array}$ & $\begin{array}{l}\text { Alkalinity } \\
(\mathrm{ppm})\end{array}$ & $\begin{array}{l}\text { Soluble Iron } \\
(\mathrm{ppm})\end{array}$ \\
\hline MW 1 & 146.0 & 19.8 & 6.90 & 184.9 & 9.97 & 12,698 & 960.0 \\
MW 2 & $3,540.0$ & 19.1 & 6.93 & 247.4 & 10.02 & 12,665 & 880.0 & 0.0 \\
MW 3 & 130.0 & 18.2 & 7.29 & 160.6 & 7.71 & 17,214 & 820.0 & 3.0 \\
MW 4 & 5.0 & 18.0 & 7.68 & 110.3 & 1.16 & 19,006 & 260.0 \\
\hline
\end{tabular}

\section{Enrichment culture development}

Two sets of enrichment cultures, A and B, were set up as per the guidelines presented by Löffler et al. (2005). Set ' $A$ ' designates biostimulation only (BS), while set ' $B$ ' designates biostimulation (BS) and bioaugmentation (BA) combined approaches for dechlorinating PCE. Both culture sets were prepared in Wheaton serum bottles $(125 \mathrm{ml}$ nominal volume) containing $75 \mathrm{ml}$ of growth medium and $20 \mathrm{ml}$ of groundwater as an inoculum which were sealed with Teflon-coated butyl rubber septa and aluminium crimp caps (Alltech, VIC, Australia). Anoxic mineral salt medium was prepared as per ATCC guidelines (American Type Culture Collection; www.atcc.org) and was amended with acetate $(5 \mathrm{mM})$ as an electron donor and PCE $(5 \mu \mathrm{l})$ as an electron acceptor. Hydrogen (5 in $95 \%$ nitrogen) was added in the headspace (5-10\% of the headspace volume of a bottle) of acetate-fed cultures at a low partial pressure of $9 \mathrm{kPa}$ (He et al. 2003). Cultures were prepared under strict anaerobic conditions and maintained in an anaerobic glove box (La-Petite, Thermo Fisher Scientific Australia, VIC) using $\mathrm{N}_{2}: \mathrm{CO}_{2}$ at the ratio of $80: 20 \%$. The mixed consortia of well-known $D h c$ strains FL2 (ATCC ${ }^{\circledR}$ BAA2098), GT (ATCC ${ }^{\circledR}$ BAA-2099) and BAV-1 $\left(\right.$ ATCC $^{\circledR}$ BAA-2100) was injected only into set B $\left(1.0 \times 10^{4}\right.$ cells/ $\mathrm{ml}$ ); however, all chlorinated compounds, vitamins and electron donors were injected into both sets from anoxic, sterilized stock solutions using a Hamilton gas tight syringe (Alltech, VIC, Australia). To minimize the contact of the inoculum with the air present in the syringes during transfers, syringes were reduced with freshly prepared, filter-sterilized aqueous sulphide solution $(0.5 \mathrm{mM})$. All experiments were repeated in duplicate and appropriate controls (without inoculum and/or electron donor, autoclaved) accompanied each experiment. Immediately upon setup, all enrichment cultures turned clear from pink tint (given by resazurin redox indicator added to the groundwater) indicating establishment of reduced conditions. Culture bottles were incubated statically at room temperature $\left(22-25^{\circ} \mathrm{C}\right)$ in the dark, and samples were analysed over 21 weeks (147 days). Since maintaining the optimum concentration of nutrients was essential for successful dechlorination, nutrient levels were monitored at predetermined time intervals by gas chromatography-mass spectrometry (GC/MS). Every 28 days, the samples from the cultures were analysed using GC/MS in order to measure the concentration of electron donors in addition to monitoring the conversion of PCE to secondary and tertiary products. Nutrient replenishments were carried out every time analyses indicated they were exhausted.

Analytical methods

Analytical procedures for both sets A and B were conducted as described by Zaan et al. (2010) with a few modifications. Chlorinated hydrocarbons were analysed in $1 \mathrm{ml}$ gas headspace using a $5975 \mathrm{C}$ gas chromatographic (GC) system equipped with a mass spectrometry (MS), flame ionizing detector (FID) detector and a Porabond Q column $(0.32 \mathrm{~mm} \times 25 \mathrm{~m})$ (Agilent Tech, Australia). The GC settings were: injector temperature $200{ }^{\circ} \mathrm{C}$; detector temperature $300{ }^{\circ} \mathrm{C}$; oven temperature $3 \mathrm{~min}$ at $40{ }^{\circ} \mathrm{C}$, followed by an increase of $10{ }^{\circ} \mathrm{C} \min ^{-1}$ to $70{ }^{\circ} \mathrm{C}$, followed by an increase of $15{ }^{\circ} \mathrm{C} \mathrm{min}^{-1}$ to $250{ }^{\circ} \mathrm{C}$ for $7 \mathrm{~min}$; and carrier gas (He) with a flow rate of $2 \mathrm{ml} \mathrm{min}^{-1}$. External standards at six different concentrations from 0 to $30 \mu \mathrm{M}$ were used for calibration. Chloride ion analyses on $1 \mathrm{ml}$ diluted cultures were performed using a Chloride Analyser 926 (Ciba-Corning, Essex, England) as per the manufacturer's protocol.

\section{Genomic DNA extraction}

Every 28 days, cells for DNA extraction were collected from enrichment cultures under sterile and anaerobic conditions with a gas tight syringe. These samples $(1 \mathrm{ml})$ were centrifuged for $30 \mathrm{~min}$ at $16,000 \mathrm{~g}, 4{ }^{\circ} \mathrm{C}$ with pellets being re-suspended in $1 \mathrm{x}$ phosphate-buffered saline (PBS) buffer and stored at $-20{ }^{\circ} \mathrm{C}$ for $1 \mathrm{~h}$ to enhance cell lysis. Genomic DNA was extracted with a Qiagen DNeasy Tissue Kit (Qiagen, NSW, Australia) according to the manufacturer's protocol with the following modifications: For improved cell lysis, $20 \mu \mathrm{l}$ of lysozyme $(100 \mathrm{mg} / \mathrm{ml})$ and $180 \mu \mathrm{l}$ enzymatic lysis buffer ( $20 \mathrm{mM}$ Tris-Cl, pH 8.0, $2 \mathrm{mM}$ sodium EDTA, $1.2 \%$ Triton $\mathrm{X}-100$ ) were added and the mixture was incubated for at least $30 \mathrm{~min}$ at $37{ }^{\circ} \mathrm{C}$ (Löffler 
et al. 2005). The quality of the genomic DNA extracts was evaluated by electrophoresis at $110 \mathrm{~V}$ for $25 \mathrm{~min}$ on a $2 \%$ w/v agarose gel stained with SYBR Safe (Invitrogen, Australia) and visualized by UV transillumination (Chemi Doc $^{\mathrm{TM}}$ MP, BioRad, NSW).

\section{Quantitative real-time PCR (qPCR)}

Copy numbers of bacterial 16S rRNA genes from both sets $A$ and $B$ were quantified using universal bacterial $341 \mathrm{~F}$ and 518 R primer set (Muyzer et al. 1993), while Dhc-specific genes were quantified using $D h c 1 \mathrm{~F}$ and $D h c 259 \mathrm{R}$ primers (Kim et al. 2010). Amplification was carried out using a MJ Mini Opticon ${ }^{\mathrm{TM}}$ real-time PCR detection system (BioRad, NSW) in reactions $(25 \mu \mathrm{l})$ containing: Sybr Green Super$\operatorname{mix}(12.5 \mu \mathrm{l})(\mathrm{BioRad}, \mathrm{NSW})$, distiled MilliQ water $(8 \mu \mathrm{l})$, forward and reverse primers $(1.25 \mu \mathrm{l} ; 6 \mathrm{pmol} / \mu \mathrm{l})$ and DNA template $(2 \mu \mathrm{l})$. The thermocycling program for $341 \mathrm{~F}$ and $518 \mathrm{R}$ was performed as described by Patil et al. (2010), while Dhc genes were quantified as per Smits et al. (2004). External standard curves showing the relationship between Dhc and $16 \mathrm{~S}$ rRNA copy numbers, and $C(T)$ values were generated with $3 \times 10$ fold serial dilutions. Amplification efficiencies were calculated from the slopes of the standard curves according to the formula: $E=10^{-1 / \text { slope }}$ (Rebrikov and Trofimov 2006). PCR efficiencies for both 16S rRNA and $D h c$ genes were between 1.8 and 1.95 with $\mathrm{R}^{2}$ of 0.98 and 0.99 , respectively (for standard curves see Fig. S1 in supplementary material). The $D h c$ target was normalized to the $16 \mathrm{~S}$ rRNA target of the same sample using the following calculations: $\Delta C(T)_{\text {sample }}=$ average $C(T)_{D h c}-$ average $C(T)_{16 \mathrm{~S}}$ RNA. For the $2^{-\Delta \Delta C(T)}$ analysis, the normalized sample values were referenced to the values obtained for time point week 1 to study the $\mathrm{x}$-fold increase in Dhc target, with the following equation: $\Delta \Delta C(T)_{\text {sam- }}$

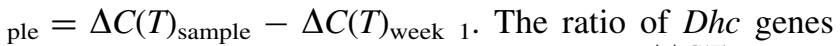
relative to the week 1 was estimated using $2^{-\Delta \Delta C(T)}$ (Livak and Schmittgen 2001; Treusch et al. 2005; Erkelens et al. 2012) (Table S1 in Supplementary material).

\section{Cell viability test}

Cell viability (live, dead and total cells) within sets A and B was measured periodically using Countess ${ }^{\mathrm{TM}}$ Automated Cell Counter (Invitrogen, Australia). Enrichment culture (10 $\mu \mathrm{l})$ was mixed with $0.4 \%$ trypan blue stain $(10 \mu \mathrm{l})$, and then the sample mixture $(10 \mu \mathrm{l})$ was loaded into the cell counting chamber slides to calculate cell count and viability as per the manufacturer's guidelines. Statistical significance was determined between different samples by $t$ test analyses. Linear regression analysis was carried out to assess the relationship between cell concentration/ml obtained from LDCC analyses and cell copy numbers obtained from qPCR analyses. All statistical analyses were carried out in SPSS version 20.

\section{Results and discussion}

Reductive dechlorination of chlorinated compounds

Groundwater from MW 1-4 in set A (BS) and set B (BSBA) was used to assess the biodegradative potential of natural microbiota upon stimulation by addition of nutrients or combined with the addition of microorganisms (Fig. 1). Monitoring of electron donor levels was carried out to ensure that optimum levels of these nutrients were maintained during the experimental period. Nutrient replenishments were carried out at week 9 (BS and BS-BA) and week 17 (BS only) as required (indicated with arrows in Fig. 1). Figure 1a shows the time course of 21 weeks (147 days) for the anaerobic PCE dechlorination by the enrichment cultures in MW 1-4. Although each of these enrichments displayed different dechlorination rates, PCE conversion began sequentially in all enrichments and the secondary products of dechlorination (TCE, cis-DCE and VC) coexisted until ethene was formed (Fig. 1a). The conversion of PCE to TCE commenced after about 25 days lag and complete conversion to $c i s$-DCE occurred by week 13. The intermediate cis-DCE was completely dechlorinated to VC by week 17, and the complete dechlorination of VC to ethene was achieved by week 21. Dechlorination intermediates, cis-DCE and VC, were temporarily accumulated in all cultures. In contrast to the rapid conversion of PCE to cis-DCE, the dechlorination of cis-DCE to VC and ethene was relatively slow.

Figure $1 \mathrm{~b}$ summarizes the results from the enrichment culture set B treated with nutrients and the Dhc consortia. In set $\mathrm{B}, \mathrm{PCE}$ dechlorination commenced within 30 days and resulted in the rapid accumulation of TCE. Between weeks 5 and 9, accumulation of TCE and cis-DCE was observed. Its subsequent disappearance was coupled to VC formation. The hydrogenolysis of chloroethenes started at week 9 and resulted in a significant decrease in TCE and cis-DCE and a corresponding increase in VC and ethene concentrations by week 13 and 17 , respectively. With set B cultures, the wells had different responses to dechlorination; however, in all cultures, PCE was dechlorinated sequentially to ethene by week 17 (119 days). In both sets of culture, the subsequent increase in chloride ion concentration observed during reductive dechlorination confirm biodegradation, since the chloride ion is a product of reductive dechlorination (Fig. 1a, b). PCE dechlorination did not progress beyond TCE and cis-DCE in the uninoculated and electron donor less autoclaved controls for both sets (data not shown). 
(a)

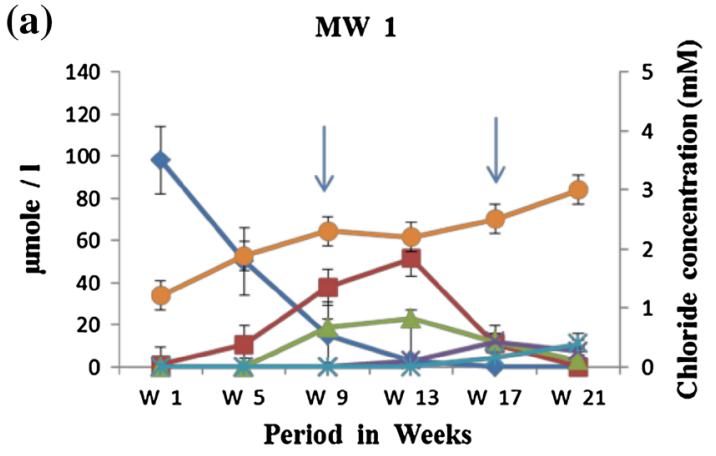

MW 3

$\leadsto$ PCE - TCE - CDCE $\longleftarrow$ VC $\lll$ Ethene $\rightleftharpoons$ Chloride
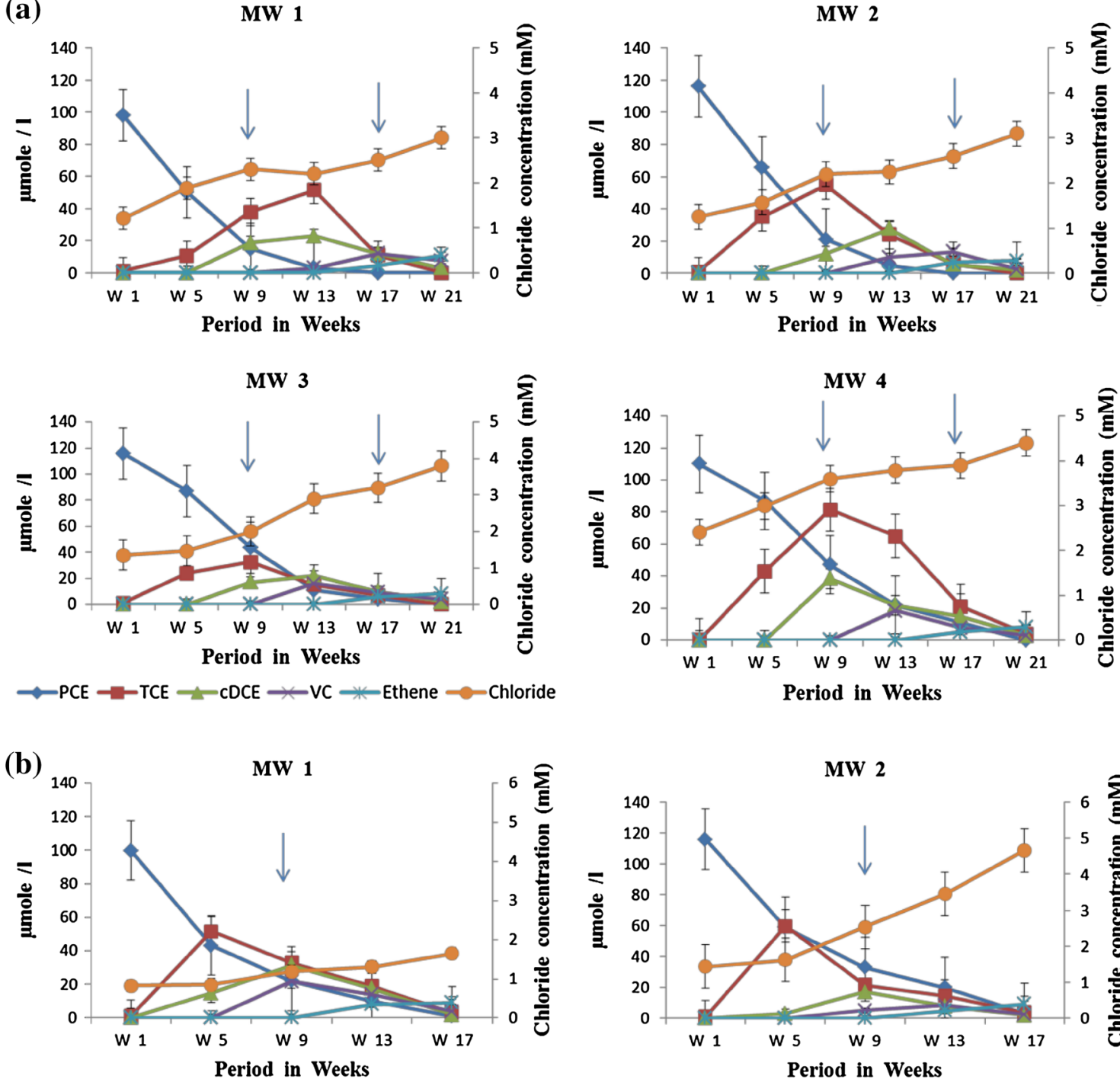

MW 3

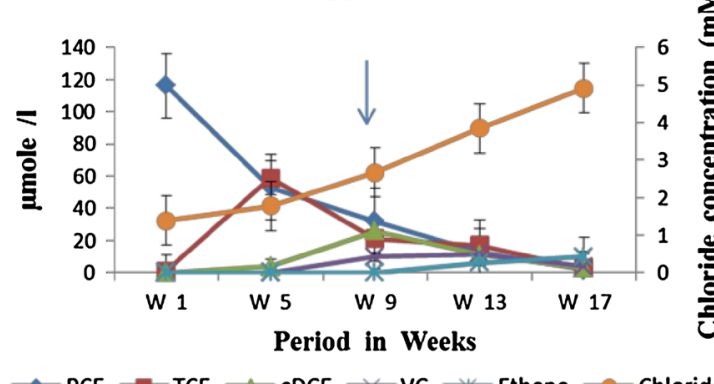

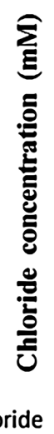

Fig. 1 PCE degradation and secondary product transformation in a BS only experiment (set A) and b BS-BA (set B) for MW 1-4 enrichment cultures. The arrow indicates the addition of electron

The detection of some initial mass imbalance with PCE to TCE conversion in some wells is not unusual as this has been observed in other similar studies (Daprato et al. 2007; Yang et al. 2005). However, in this study, the system was
MW 2
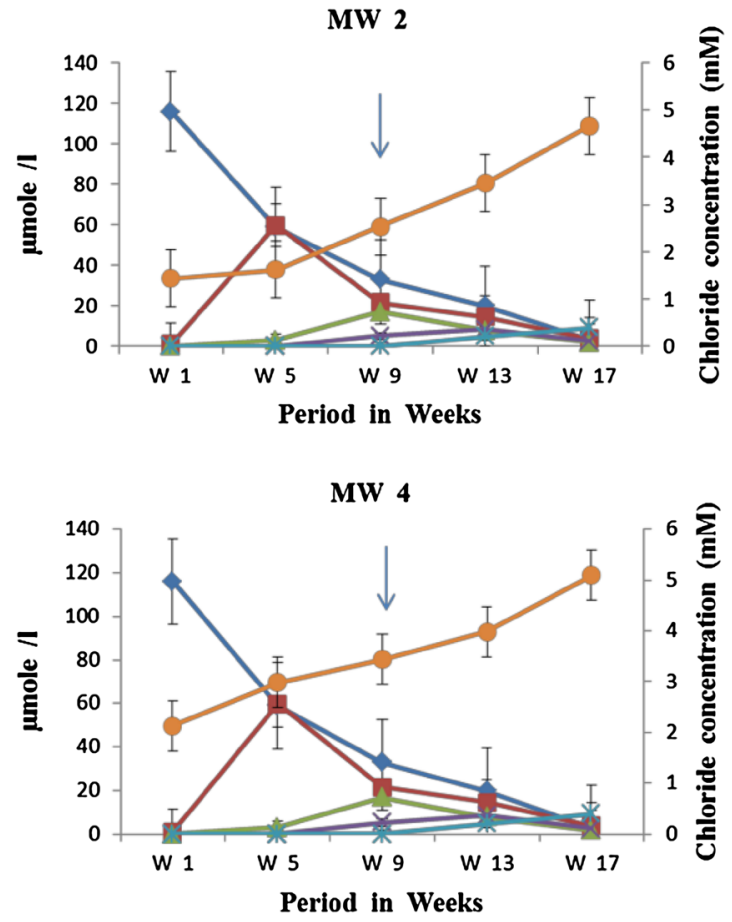

donors. Data are the average of the duplicates (duplicates differed by $<10 \%)$. Error bars indicate standard error $(n=2)$

stabilized after 20 days of incubation. In BS cultures, the electron donors enhanced complete dechlorination, indicating the presence of a native dechlorinating population whose dechlorinating activity was probably limited by the 
lack of electron donors in the groundwater. Both BS and BS-BA treatments resulted in complete PCE conversion to ethene, but augmentation with $D h c$ consortia followed by stimulation was necessary to accelerate the rate and time of dechlorination in set B. Previously, a few studies carried out using only the biostimulation approach failed to attain complete dechlorination of PCE under laboratory and field conditions (Ibbini et al. 2010; Major et al. 2002; Lendvay et al. 2003). Incomplete dechlorination poses a major threat as accumulation of the intermediate dechlorination product $\mathrm{VC}$ is more toxic and carcinogenic than PCE and TCE (ASTDR 2007). Partial dechlorination is usually observed if the organisms that reductively dechlorinate ethene are not present or active at the contaminated site. However, this study reports the complete dechlorination of PCE via biostimulation, suggesting the presence of active indigenous dechlorinators in the groundwater collected from contaminated site. Fluxes of both $\mathrm{H}_{2}$ and acetate might have controlled microbial redox processes in the biostimulation cultures that can synergistically sustain the complete reduction in PCE to benign ethene. Biostimulation increases the flux of $\mathrm{H}_{2}$ and acetate (He et al. 2002), but competition for reducing equivalents, in particular for $\mathrm{H}_{2}$ often limits its success (Sung et al. 2006). However, native dechlorinators stimulated in this study showed greater electron donor versatility towards acetate and $\mathrm{H}_{2}$, indicating that an ecological niche in a well-controlled laboratory environment existed for organisms that could derive energy from the complete dechlorination of chlorinated solvents to ethene. To date, there is limited evidence using laboratory mixed cultures indicating that there might be organisms other than $D h c$ that can synergistically sustain complete reduction in PCE to ethene (Dong et al. 2011; Lee et al. 2011).

Growth-linked reductive dechlorination of chlorinated ethenes

16S rRNA gene-targeted qPCR was performed on sets A and $\mathrm{B}$ to study the correlation between rate of reductive dechlorination and growth of dechlorinating population in response to the BS and BS-BA treatments. Dechlorination of all four chlorinated ethenes was accompanied by an increase in 16S rRNA gene copies (Fig. 2). During BS, cell copies of indigenous microorganisms in enrichments MW 1-4 increased from week 1 to 21 from $2.01 \times 10^{4}$ to $1.43 \times 10^{5} ; 1.53 \times 10^{4}$ to $1.66 \times 10^{5} ; 2.63 \times 10^{4}$ to $1.79 \times 10^{5}$ and $2.27 \times 10^{4}$ to $1.77 \times 10^{5}$ cells $/ \mathrm{ml}$, respectively (Fig. 2a). Cell density in cultures MW 1 and 3 dropped in week 9 but increased by week 13. Most likely, the electron donors had become depleted as both dechlorination and growth accelerated by week 13 , when nutrients were replenished. This suggests that the growth of dechlorinators is dependent on electron donors and dechlorination can slow down if these substrate are depleted (Cichocka et al. 2010). For the BS-BA experiment in set $\mathrm{B}$, a mixed consortia of Dhc strains $\left(1 \times 10^{4}\right.$ cells/ $\mathrm{ml}$ ) was added into PCE-contaminated groundwater enrichment cultures followed by stimulation with electron donors. In enrichments MW 1-4, initial total cell concentration at week 1 was $3.65 \times 10^{4}, 3.89 \times 10^{4}, 3.08 \times 10^{4}$, $7.21 \times 10^{4}$ cells $/ \mathrm{ml}$ which increased significantly to $7.98 \times 10^{5}, 7.43 \times 10^{5}, 6.98 \times 10^{5}, 8.09 \times 10^{5}$ cells $/ \mathrm{ml}$ by the end of dechlorination in week 17 (Fig. 2b). Similar to set A, a decrease in total cell copies in set B was observed for enrichments MW 3 and 4 during week 9 which increased in week 13 after nutrient replenishment. This emphasizes the fact that nutrients should be added to sustain native dechlorinators and $D h c$ activity throughout the process to achieve complete dechlorination. There was a distinct difference in the cell numbers between the two sets. The BS-BA culture contained at least an order of magnitude greater numbers of cells than in BS only cultures which is consistent with the higher ethene production rates in the augmented cultures (Fig. 2). However, over the experimental period, the number of cell copies did not increase significantly (week $1 ; 2.0 \times 10^{4} \mathrm{cell} / \mathrm{ml}$ and week $213.21 \times 10^{4}$ cells $\left./ \mathrm{ml}\right)$ in the control sets where inoculum and electron donors were omitted from the system.

Analysis of groundwater from the BS enrichment culture with universal bacterial primers amplified $16 \mathrm{~S}$ rRNA genes from indigenous dechlorinators; however, Dhcspecific 16S rRNA gene primers failed to detect $D h c$ population (Fig. 3a). This indicated the absence of $D h c$ species in the groundwater collected from PCE-contaminated site, although it was also possible that they could have been below the detection threshold of the primers used. Upon stimulation, enrichment cultures MW 1-4 showed $\sim 3.86-, 2.58-, 2.96-$ and 3.73-fold increase in the abundance of $16 \mathrm{~S}$ rRNA genes in set $\mathrm{A}$ at week 21 compared to week 1, respectively (Fig. 3a). As the absolute amounts of $16 \mathrm{~S}$ rRNA copies measured in the same cultures stayed constant at week 1 , the increase in the gene copies by the end of week 21 was found to be statistically significant ( $t$ test, $95 \%$ confidence level). In order to analyse whether the $D h c$ species might be induced in set $\mathrm{B}$, the Dhc target gene was normalized to the 16S rRNA target of the same culture (Treusch et al. 2005). Figure 3b displays the relative increase in $D h c$ genes normalized to $16 \mathrm{~S}$ rRNA over the period of 17 weeks. While the abundance of $16 \mathrm{~S}$ rRNA and $D h c$ genes was largely the same at week 1, bioaugmentation followed by stimulation resulted in approximately twofold and threefold increase in the abundance of 16S rRNA and Dhc genes by week 17, respectively (Fig. 3b). The comparison of the 
Fig. 2 Quantitative estimation of population abundance by qPCR in two PCE-

dechlorinating enrichment sets of a BS only and $\mathbf{b}$ BS-BA over the period of 21 weeks. Error bars indicate standard error $(n=2)$ (a)

Set A (BS)

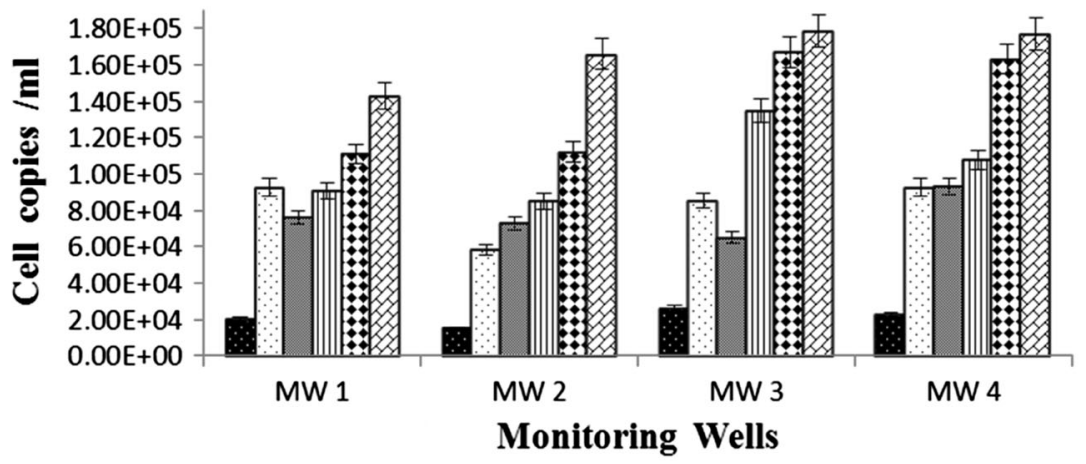

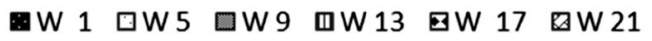

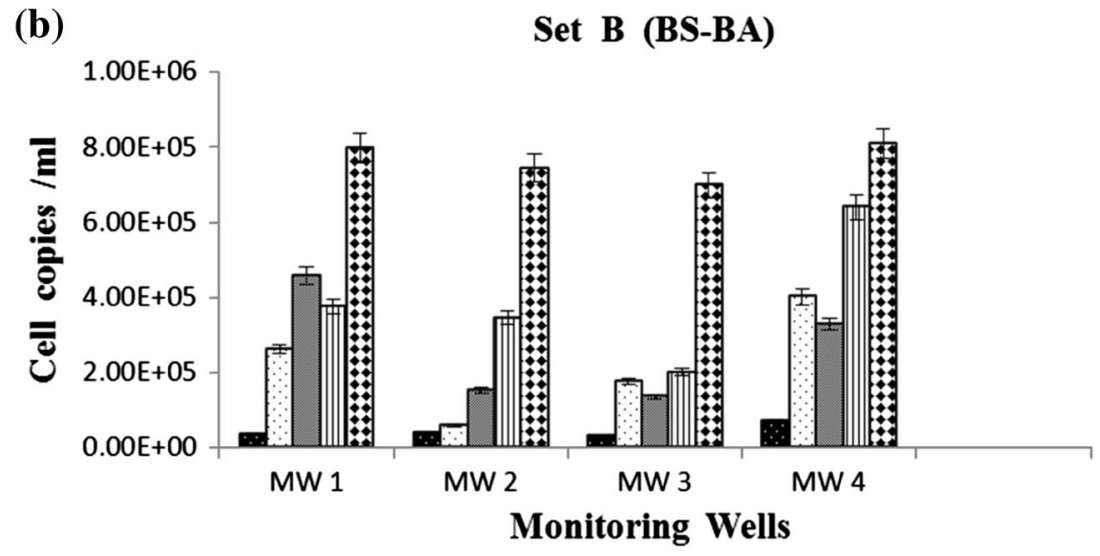

bioremediation treatments and the quantitative analyses showed that rapid dechlorination in the BS-BA cultures could be enhanced due to simultaneous increase in $D h c$ and native dechlorinating microorganisms. The outcome of competition between $D h c$ and other chlorinated ethene respirers over electron donors, especially $\mathrm{H}_{2}$ could possibly influence the rate and extent of PCE dechlorination (Becker 2006). The results obtained therefore suggested a syntrophic association between $D h c$ species and other native dechlorinators existed to carry out PCE reduction. Previously, an increase in $D h c$ gene copy numbers has been associated with enhanced reductive dechlorination of chlorinated compounds (Cichocka et al. 2010; Cupples 2008; Duhamel and Edwards 2006; Smits et al. 2004; Sung et al. 2006). Therefore, a approximately threefold increase in $D h c$ gene abundance over a approximately twofold increase in 16S rRNA genes might have synergistically contributed to the complete and rapid dechlorination of PCE in set B. BS and BS-BA treatments in enrichment cultures MW 1-4 enhanced dechlorination at different rates (Fig. 2) which could be due to varying abundance and response level of dechlorinators present at respective wells (Fig. 3).
Cell viability assay

The dechlorination process depends upon the presence and viability of an appropriate microbial population to facilitate the reaction (Major et al. 2002). The higher the viability of cells, the greater the ability of dechlorinating cells to reproduce in controlled anaerobic environment and therefore to reduce PCE by substrate utilization. Therefore, in addition to $\mathrm{qPCR}$, we conducted cell viability assays to quantitatively distinguish between live and dead bacterial cells based on a total cell sample in a mixed population. For biostimulation, total cell concentration in enrichments MW 1-4 increased from weeks 1 to 21 from $2.05 \times 10^{4}$, $1.52 \times 10^{4}, 2.69 \times 10^{4}, 2.23 \times 10^{4}$ to $1.41 \times 10^{5}$, $1.67 \times 10^{5}, 1.8 \times 10^{5}, 1.76 \times 10^{5}$ cells $/ \mathrm{ml}$, respectively (Fig. 4a). The overall cell viability (live/dead cells based on total cell counts) throughout the dechlorination process was higher in MW 1 and $2(80 \%)$ than in MW $3(75 \%)$ and MW 4 (70 \%).

For the BS-BA enrichments MW 1-4, initial total cell concentration at week 1 was $3.64 \times 10^{4}, 3.87 \times 10^{4}$, $3.1 \times 10^{4}, \quad 7.24 \times 10^{4}$ cells $/ \mathrm{ml}$ which increased to $7.96 \times 10^{5}, 7.42 \times 10^{5}, 6.98 \times 10^{5}, 8.1 \times 10^{5}$ cells $/ \mathrm{ml}$ 
(a)
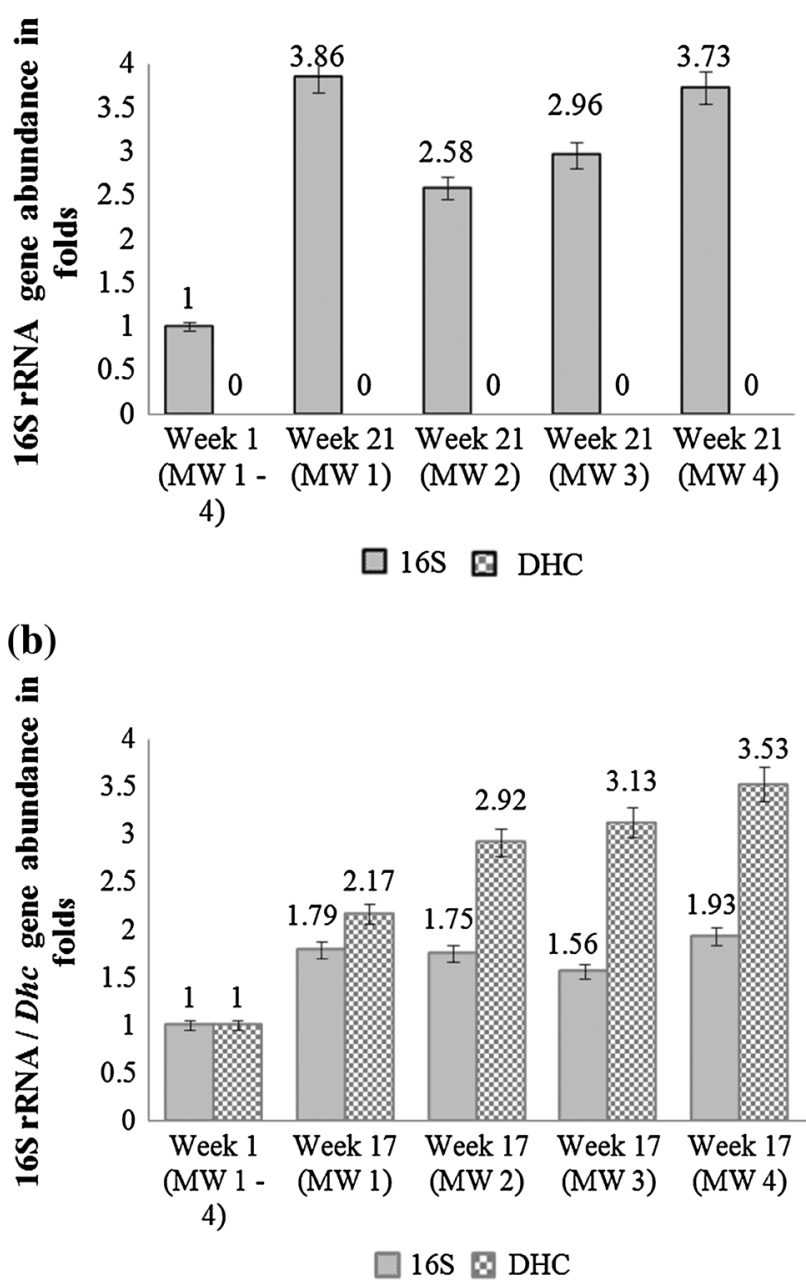

Fig. 3 Relative abundance of $D h c$ gene copies referenced to $16 \mathrm{~S}$ rRNA of indigenous bacteria in the a set A with BS only and $\mathbf{b}$ set B with BS-BA microcosm experiments using qPCR analysis. Dhcspecific 16S rRNA genes failed to amplify in set A, indicating its absence in the groundwater. The fold increase over 21 weeks was calculated with normalized sample values and referenced to the week 1 values. Error bars indicate standard error $(n=2)$

by the end of dechlorination in week 17 (Fig. 4b). Cell viability during the incubation period was approximately $75,82,78$ and $79 \%$ in cultures MW 1-4, respectively. Although total cell numbers of native cells increased in the $\mathrm{BS}$, the numbers were at least an order of magnitude lower than BS-BA. In control samples (week 1;2.0 × $10^{4}$ cells/ $\mathrm{ml}$ and week $21 ; 3.69 \times 10^{4}$ cells $\left./ \mathrm{ml}\right)$, there was no significant increase in cell count and viability over the experimental period. In general, the total cell concentration within both sets increased with increasing cell viability as dechlorination progressed. Overall, the data indicated that higher cell viability can be correlated with active dechlorination and presumably growth within a microbial community.
We compared our total cell concentration results within both sets obtained using cell counter and qPCR (Figs. 2, 4). The comparative analyses demonstrated similar trend of increased total cell copies as dechlorination progressed, showing a good correlation between the LDCC and qPCR quantitative data $(r>0.95)$. In terms of methodology, this study therefore demonstrates the usefulness of using alternative low-cost quantification technique such as LDCC for monitoring total cell numbers and viability of organisms involved in reductive dechlorination. The LDCC assay provided insights into dechlorinating microbial viability which was highly similar to that obtained from qPCR analyses. LDCC could be a cheaper and faster alternative to the more rigorous qPCR method for quantitative analysis as it requires substantially less financial outlay compared to qPCR. It is also more portable and bioremediation practitioners can easily be trained in its use without the need for them to have a scientific background unlike in qPCR. Therefore, this could be of particular interest during field trials, where quick monitoring of microbial activities needs to be done to assess the progress of bioremediation.

\section{Feasibility of bioremediation treatments}

Bioremediation, both natural and enhanced, has proven to be a powerful approach for remediating chlorinated solvents (Cupples et al. 2004; Lee et al. 1997; Maymó-Gatell et al. 1997). But in recent years, there has been considerable debate over whether bioaugmentation is beneficial over biostimulation, particularly when it comes to commercial site application (ESTCP 2005). The decision to bioaugment or biostimulate is a function of several factors including economic, political and technical considerations. Within the last decade, basic research on natural microbial dechlorination mechanisms has shown that degradation of chlorinated compounds can be practically achieved by stimulating microbial reductive dechlorination (Ellis et al. 2000). However, conditions in some groundwater wells may not be completely anoxic, as observed in MW1-MW3 (Table 1) in this study. In order to ensure efficient microbial reductive dechlorination, low- $\mathrm{H}_{2}$-generating organic substrates such as acetate, lactate or molasses could be added to create the required anaerobic conditions (Aulenta et al. 2006; ESTCP 2004; Fennell et al. 1997; He et al. 2002). Some researchers have stated that at the vast majority of sites, the desired activities will occur by stimulating existing environment and it is simply a matter of more time and more electron donors (Koenigsberg et al. 2003; Suthersan et al. 2002). Some environmental regulatory bodies are also wary of adding organisms, particularly mixed cultures in which not all of the organisms are fully characterized (Ball 2012). In such scenarios, bioremediation needs to be carried out by stimulating already present 
Fig. 4 Cell viability assay of a BS only (set A) and b BS-BA experiment (set B) for MW 1-4 enrichment cultures over the period of 21 weeks. Error bars indicate standard error $(n=2)$ (a)

Set A (BS)

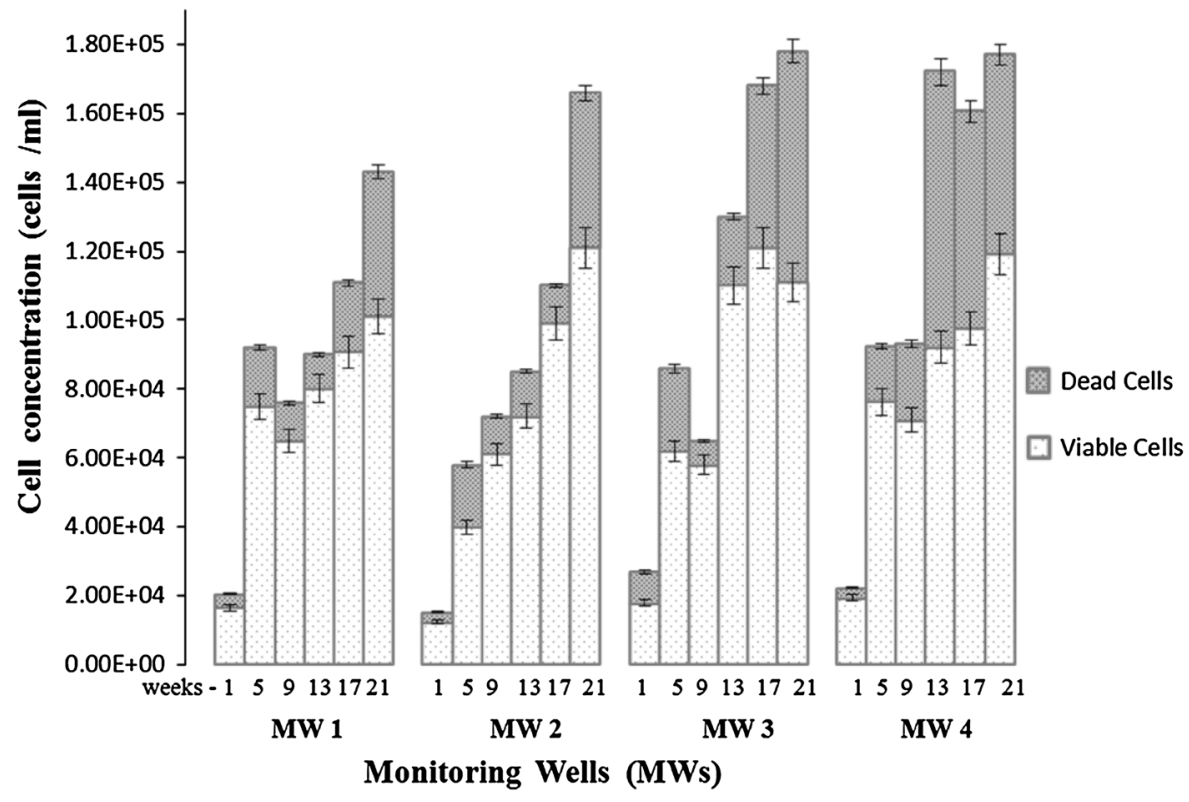

(b)

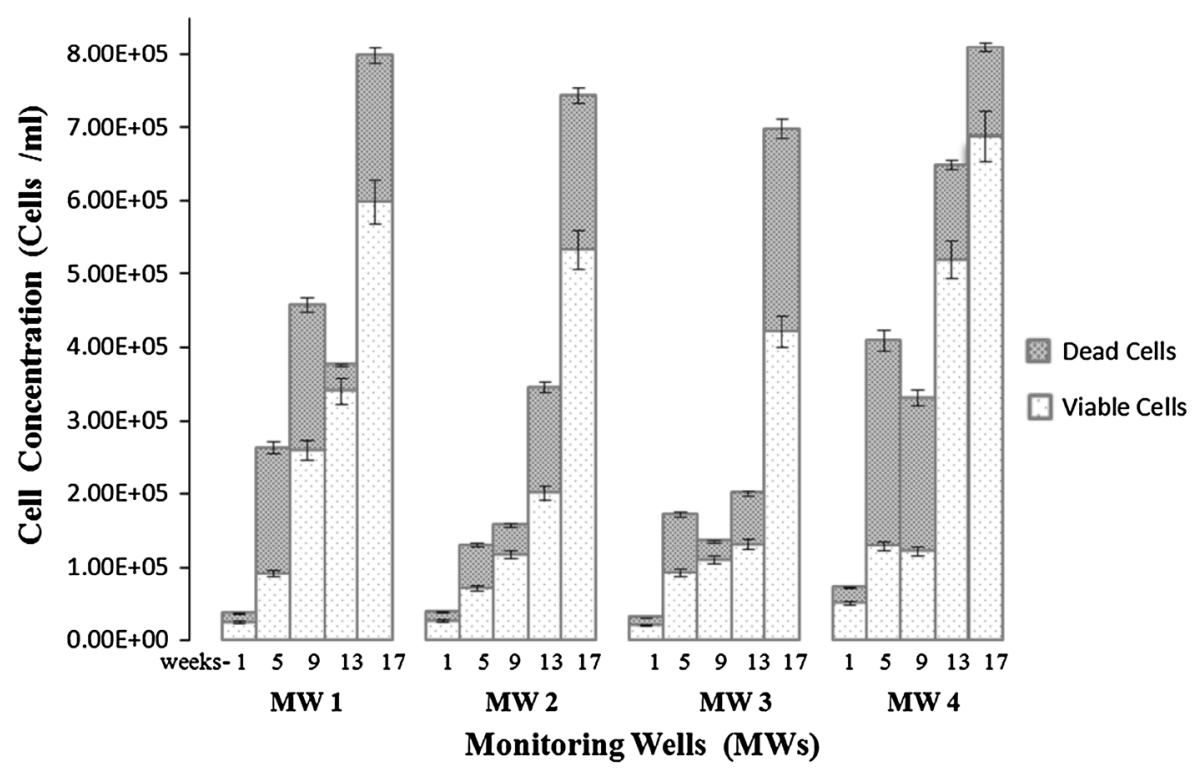

native microorganisms that are well suited for subsurface environments and well distributed spatially within the subsurface.

Studies demonstrating biostimulation followed by bioaugmentation with an enrichment culture capable of complete dechlorination of PCE to ethene indicated some benefits of this strategy over a biostimulation only approach (Ellis et al. 2000; He et al. 2003; Sung et al. 2006; Cichocka et al. 2010; Ibbini et al. 2010; Major et al. 2002). Bioaugmentation may offer a solution for contaminated sites where dechlorination is not occurring naturally (where the appropriate organisms are lacking) or where it is too slow to be practical (very low numbers of dechlorinating organisms) (Major et al. 2002). Even at sites where competent $D h c$ are present, bioaugmentation may decrease the lag time prior to the onset of dechlorination. This is particularly true for sites desiring rapid remediation due to an impending property transaction and stringent regulatory or commercial deadlines. Although costs for the culture solutions needed for bioaugmentation are decreasing, the inoculum itself can still be a significant expense at relatively large sites. The choice of electron donor can also affect the decision whether to or not to bioaugment. Bioaugmentation with $D h c$-containing cultures may not 
always ensure that complete dechlorination of PCE can be sustained in the presence of PCE to cis-DCE dechlorinating specialist unless adequate electron donor can be specifically delivered to Dhc populations (Becker 2006). In order for bioaugmentation to succeed, a niche must be created that is specifically available for augmented microorganisms (Ellis et al. 2000). The fate of electron donors and their fermentation products including not only $\mathrm{H}_{2}$ but also other intermediates is of critical importance for understanding the response of dechlorinating communities. Using highstrength soluble donors (such as lactic acid, molasses) added at frequent intervals may make bioaugmentation more attractive, because it is relatively expensive to operate the system for even a few months without achieving complete dechlorination (ESTCP 2005). On the other hand, bioaugmentation may be less attractive when using longlasting, less soluble donors (such as chitin, HRC ${ }^{\mathrm{TM}}$ or vegetable oil), because the time and additional operational and maintenance needed to achieve complete dechlorination may represent a relatively small incremental cost (Ibbini et al. 2010). Overall, this fundamental information on the ecology and biophysical interaction of community members involved in the partial and complete dechlorination process should help to better understand and design appropriate remediate strategies for chloroethene-contaminated sites.

\section{Conclusion}

This study reported a comparative pre-evaluation of BS and BS-BA approaches for the PCE remediation on groundwater samples obtained from a PCE-contaminated site. Both approaches resulted in complete dechlorination in samples, with the BS-BA approach resulting in a shorter dechlorination time frame. However, even when bioaugmentation cannot be applied either due to costs or legislative difficulties, biostimulation strategy can still be effectively applied leading to remediation of site. $16 \mathrm{~S}$ rRNA-based qPCR and LDCC analyses were used to assess the dechlorinating community potential during PCE dechlorination. Regression analysis showed that LDCC represents a low-cost and 'low-tech' approach to monitoring the dechlorinating potential of community resulting in substantial time and financial savings. Given the variety of environmental factors expected in different contaminated sites, this study has demonstrated the value of site-specific pre-evaluation of PCE-contaminated sites using a combination of microbiological and chemical approaches; a crucial step to design a successful in situ fieldbased bioremediation strategy.

Acknowledgments The authors thank the team of Environmental Earth Sciences Pty Ltd, Victoria, for providing groundwater samples.
Our sincere thanks also go to the Flinders University of South Australia for offering a scholarship to the first author.

\section{References}

ASTDR (2007) Agency for Toxic Substances and Drug Registry. ASTDR, Atlanta, GA. http://www.astdr.cdc.gov. Accessed 23 March 2011

Aulenta F, Majone M, Tandoi V (2006) Enhanced anaerobic bioremediation of chlorinated solvents: environmental factors influencing microbial activity and their relevance under field conditions. J Chem Technol Biotechnol 81:1463-1474

Ball AS (2012) The use of microorganisms for bioremediation. Proceedings of Organisation for Economic Co-operation and Development (OECD) on environmental use of microorganisms, Paris

Ballapragada BS, Stensel HD, Puhakka JA, Ferguson JF (1997) Effect of hydrogen on reductive dechlorination of chlorinated ethenes. Environ Sci Technol 31:1728-1734

Becker JG (2006) A modeling study and implications of competition between Dehalococcoides ethenogenes and other tetrachloroethene respiring bacteria. Environ Sci Technol 40:4473-4480

Cheng D, Chow WL, He J (2010) A Dehalococcoides-containing coculture that dechlorinates tetrachloroethene to trans-1,2-dichloroethene. ISME J 4:88-97

Cichocka D, Nikolausz M, Haest PJ, Nijenhuis I (2010) Tetrachloroethene conversion to ethene by a Dehalococcoides containing enrichment culture from Bitterfeld. FEMS Microbiol Ecol 72:297-310

Cupples AM (2008) Real-time PCR quantification of Dehalococcoides populations: methods and applications. J Microbiol Meth 72:1-11

Cupples AM, Spormann AM, McCarty PL (2003) Growth of a Dehalococcoides-like microorganism on vinyl chloride and cisdichloroethene as electron acceptors as determined by competitive PCR. Appl Environ Microbiol 69:953-959

Cupples AM, Spormann AM, McCarty PL (2004) Comparative evaluation of chloroethene dechlorination to ethene by $D e$ halococcoides-like microorganisms. Environ Sci Technol 38:4768-4774

Daprato RC, Löffler FE, Hughes JB (2007) Comparative analysis of three tetrachloroethene to ethene halorespiring consortia suggests functional redundancy. Environ Sci Technol 41:2261-2269

Dong Y, Butler EC, Philp RP, Krumholz LR (2011) Impacts of microbial community composition on isotope fractionation during reductive dechlorination of tetrachloroethylene. Biodegradation 22:431-444

Duhamel M, Edwards EA (2006) Microbial composition of chlorinated ethene-degrading cultures dominated by Dehalococcoides. FEMS Microbiol Ecol 58:538-549

Duhamel M, Mo K, Edwards EA (2004) Characterization of a highly enriched Dehalococcoides-containing culture that grows on vinyl chloride and trichloroethene. Appl Environ Microbiol 70:5538-5545

Ellis DE, Lutz EJ, Odom JM, Buchanan RJ, Bartlett CL, Lee MD, Harkness MR, DeWeerd KA (2000) Bioaugmentation for accelerated in situ anaerobic bioremediation. Environ Sci Technol 34:2254-2260

Environmental Security Technology Certification Program (ESTCP) (2004) Principles and practices of enhanced anaerobic bioremediation of chlorinated solvents. Arlington, Virginia. http:// costperformance.org/remediation/pdf/principles_and_practices_ bioremediation.pdf. Accessed 19 February 2011 
Environmental Security Technology Certification Program (ESTCP) (2005) Bioaugmentation for remediation of chlorinated solvents: Technology development, status and research needs. Arlington, Virginia. http://www.cluin.org/download/remed/Bioaug2005. pdf. Accessed 19 February 2011

Erkelens M, Adetutu EM, Taha M, Tudaro-Aherobo L, Antiabong J, Provata A, Ball AS (2012) Sustainable remediation-the application of bioremediated soil for use in the degradation of TNT chips. J Environ Manag 110:69-76

Ernst T (2009) Use of Dehalococcoides to bioremediate groundwater contaminated with chlorinated Solvents. Basic Biotechnol 5:72-77

Fennell DE, Gossett JM, Zinder SH (1997) Comparison of butyric acid, ethanol, lactic acid, and propionic acid as hydrogen donors for the reductive dechlorination of tetrachloroethene. Environ Sci Technol 31:918-926

He J, Sung Y, Dollhopf ME, Fathepure BZ, Tiedje JM, Löffler FE (2002) Acetate versus hydrogen as direct electron donors to stimulate the microbial reductive dechlorination process at chloroethene-contaminated sites. Environ Sci Technol 36:3945-3952

He J, Ritalahti KM, Aiello MR, Löffler FE (2003) Complete detoxification of vinyl chloride by an anaerobic enrichment culture and identification of the reductively dechlorinating population as a Dehalococcoides Species. Appl Environ Microbiol 69:996-1003

He J, Sung Y, Krajmalnik-Brown R, Ritalahti KM, Löffler FE (2005) Isolation and characterization of Dehalococcoides sp. strain FL2, a trichloroethene (TCE)- and 1,2-dichloroethene-respiring anaerobe. Environ Microbiol 7:1442-1450

Hendrickson ER, Payne JA, Young RM, Starr MG, Perry MP, Fahnestock S, Ellis DE, Ebersole RC (2002) Molecular analysis of Dehalococcoides 16S ribosomal DNA from chloroethenecontaminated sites throughout North America and Europe. Appl Environ Microbiol 68:485-495

Ibbini J, Santharam S, Davic LC, Erickson LE (2010) Laboratory and field scale bioremediation of tetrachloroethene (PCE) contaminated groundwater. J J Mech Indus Eng 4:35-44

Kim BH, Baek KH, Cho DH, Sung Y, Koh SC, Ahn CY, Oh HM, Kim HS (2010) Complete reductive dechlorination of tetrachloroethene to ethene by anaerobic microbial enrichment culture developed from sediment. Biotechnol Lett 32(12):18291835

Koenigsberg S, Willet A, Rohdenburg P (2003) Biological treatment of residual DNALP with a slow release electron donor HRC-X TM. In: Gavasker AR, Chen ASC (eds) Remediation of chlorinated and recalcitrant compounds. Battelle Press, Columbus

Lee MD, Quinton GE, Beeman RE, Biehle AA, Liddle RL (1997) Scale up issues for in situ anaerobic tetrachloroethene bioremediation. J Indus Microbiol Biotechnol 18:106-115

Lee MD, Buchanan RJ, Ellis DE (2000) Laboratory studies using edible oils to support reductive dechlorination. In: Wickranayake GB, Gavaskar AR, Alleman BC, Magar VS (eds) Bioremediation and phytoremediation of chlorinated and recalcitrant compounds. The second International Conference on remediation of chlorinated and recalcitrant compounds, Monterey, CA, pp 77-84

Lee J, Lee TK, Löffler FE, Park J (2011) Characterization of microbial community structure and population dynamics of tetrachloroethene dechlorinating tidal mudflat communities. Biodegradation 22:687-698

Lendvay JM, Löffler FE, Dollhopf M, Aiello MR, Daniels G, Fathepure BZ, Gebhard M, Heine R, Helton R, Shi J, Krajmalnik-Brown R, Major CL, Barcelona MJ, Petrovskis E, Hickey R, Tiedje JM, Adriaens P (2003) Bioreactive barriers: a comparison of bioaugmentation and biostimulation for chlorinated solvent remediation. Environ Sci Technol 37:1422-1431

Livak KJ, Schmittgen TD (2001) Analysis of relative gene expression data using real time quantitative PCR and the $2^{-\Delta \Delta C T}$ method. Methods 25:402-408

Löffler FE, Edwards EA (2006) Harnessing microbial activities for environmental cleanup. Curr Opin Biotechnol 17:274-284

Löffler FE, Sanford RA, Ritalahti KM (2005) Enrichment, cultivation and detection of reductively dechlorinating bacteria. Methods Enzymol 397:77-111

Major DW, McMaster ML, Cox EE, Edwards EA, Dworatzek SM, Hendrickson ER, Starr MG, Payne JA, Buonamici LW (2002) Field demonstration of successful bioaugmentation to achieve dechlorination of tetrachloroethene to ethene. Environ Sci Technol 36:5106-5116

Maymó-Gatell X, Chien Y, Gossett JM, Zinder SH (1997) Isolation of a bacterium that reductively dechlorinates tetrachloroethene to ethene. Science 276:1568-1571

Müller JA, Rosner BM, von Abendroth G, Meshulam-Simon G, McCarty PL, Spormann AM (2004) Molecular identification of the catabolic vinyl chloride reductase from Dehalococcoides sp. Strain VS and its environmental distribution. Appl Environ Microbiol 70:4880-4888

Muyzer G, de Waal EC, Uitterlinden A (1993) Profiling of complex microbial populations using denaturing gradient gel electrophoresis analysis of polymerase chain reaction-amplified genes coding for 16S rRNA. Appl Environ Microbiol 59:695-700

Patil SS, Ward AJ, Kumar MS, Ball AS (2010) Utilising bacterial communities associated with digested piggery effluent as a primary food source for the batch culture of Moina australiensis. Bioresource Technol 101:3371-3378

Rebrikov DV, Trofimov DYu (2006) Real-time PCR: a review of approaches to data analysis. Appl Biochem Microbiol 42(5):455-463

Ritalahti KM, Hatt JK, Petrovskis E, Löffler FE (2010) Groundwater sampling for nucleic acid biomarker analysis. In: Timmis KN (ed) Handbook of hydrocarbon and lipid microbiology. Springer, Berlin, Heidelberg, pp 3407-3418

Schaefer CE, Lippincott DR, Steffan RJ (2010) Field-scale evaluation of bioaugmentation dosage for treating chlorinated ethenes. Groundwater Monit R 30:113-124

Smits THM, Devenoges C, Szynalski K, Maillard J, Holliger C (2004) Development of a real-time PCR method for quantification of the three genera Dehalobacter, Dehalococcoides, and Desulfitobacterium in microbial communities. J Microbiol Meth 57:369-378

State Coalition for Remediation of Drycleaners (SCRD) (2007) A chronology of historical developments in drycleaning. http:// www.drycleancoalition.org/ownload/drycleaning-historical_ developments.pdf. Assessed 19 February 2011

Sung Y, Fletcher KE, Ritalahti KM, Apkarian RP, Ramos-Hernandez N, Sanford RA, Mesbah NM, Loffler FE (2006) Geobacter lovleyi sp. nov. Strain SZ, a novel metal-reducing and tetrachloroethene-dechlorinating bacterium. Appl Environ Microbiol 72:2775-2782

Suthersan S, Lutes CC, Palmer PL, Lenzo F, Payne FC, Liles DD, Burdick J (2002) Technical protocol for using soluble carbohydrates to enhance reductive dechlorination of chlorinated aliphatic hydrocarbons. Washington, DC. http://www.cluin.org/ download/contaminantfocus/tce/BioTechProtocol.pdf. Assessed 23 March 2011

Treusch AH, Leininger S, Kletzin A, Schuster SC, Kenk SP, Schleper C (2005) Novel genes for nitrite reductase and Amo-related proteins indicate a role of uncultivated mesophilic crenarchaeota in nitrate cycling. Environ Microbiol 7(12):1985-1995

Yang Y, Pesaro M, Sigler W, Zeyer J (2005) Identification of microorganisms involved in reductive dehalogenation of 
chlorinated ethenes in an anaerobic microbial community. Water Res 39:3954-3966

Zaan B, Hannes F, Hoekstra N, Rijnaarts H, de Vos WM, Smidt H, Gerritse J (2010) Correlation of Dehalococcoides 16S rRNA and chloroethene-reductive dehalogenase genes with geochemical conditions in chloroethene-contaminated groundwater. Appl Environ Microbiol 76:843-850 